\title{
USHER SYNDROME-THE MOST COMMON REASON FOR DEAF-BLINDNESS
}

\author{
Catherina Bommert ${ }^{1}$, Elitsa Hristova ${ }^{2}$, Christina Grupcheva ${ }^{1}$ \\ ${ }^{1}$ Department of Ophthalmology and Visual Sciences, Faculty of Medicine, \\ Medical University of Varna \\ ${ }^{2}$ Department of Physiotherapy, Rehabilitation, Thalassotherapy and Occupational \\ Diseases, Faculty of Public Health, Medical University of Varna
}

\begin{abstract}
Deaf-blindness is a serious disability, which affects all aspects of life. The most common condition combining deafness and blindness is the Usher syndrome (USH), which is traditionally divided into three major clinical subtypes, including Usher syndrome type 1, Usher syndrome type 2 , and Usher syndrome type 3. The frequency of USH occurrence is often undervalued. To date, five genes for USH1 have been identified, three genes are involved in USH2, and one gene in USH3. In summary, USH can be a multisensory impairment associated with hearing impairment, progressive retinal degeneration, and vestibular dysfunction. Management of these patients requires interdisciplinary approach and collaboration.
\end{abstract}

Keywords: Usher syndrome, retinal degeneration, deaf-blindness, visual impairment, congenital hearing loss

\section{INTRODUCTION}

Hellen Keller is a great example and symbol of a person who can overcome deaf-blindness and still adapt to the society. However, every day we meet patients who have either deafness or blindness. When those two disabilities combine, the person is really isolated from the world. They can develop gradually or simultaneously, or most devastatingly—be present at birth. Usher syndrome (USH) comprises a series

\footnotetext{
Address for correspondence:

Christina N. Grupcheva

Medical University of Varna

55 Marin Drinov St

9002 Varna, Bulgaria

e-mail:cgrupcheva@gmail.com
}

Received: June 20, 2021

Accepted: June 29, 2021 of inherited conditions characterized by the combination of hearing impairment and visual impairment by progressive retinal degeneration in the form of retinopathy pigmentosa.

Usher syndrome not only comprises more than half of cases of deaf-blindness, but it is also the most common cause of combined vision and hearing loss (1). The frequency of occurrence, which is currently reported to be 4 to 17 per 100,000 , may often be undervalued (2).

Besides the usually congenital hearing loss, retinitis pigmentosa is a gradual progressive process and is being first noticed in early childhood to the midteenage years (2).

Nevertheless, USH encompasses more than just congenital deafness and retinitis pigmentosa. In addition, there may also be degeneration of the central nervous system with variable presentation of psychiatric illnesses, mental retardation, olfactory sensitivity loss, as well as aphasia, and other conditions $(3,4)$. 
The syndrome can be traditionally divided into three major clinical subtypes, Usher syndrome type 1 (USH1), Usher syndrome type 2 (USH2), and Usher syndrome type 3 (USH3). The subtypes are associated with distinct genetic causes due to at least 12 genetic chromosomal loci assigned to the three types (5-7). Each of the three clinical USH types is autosomal recessive in inheritance $(6,8,9)$.

Usher syndrome is determined by mutations in specific genes, with five genes currently known for USH1, three genes for USH2, and one gene for USH3 $(4,10)$.

A variety of proteins are encoded by these aforementioned genes, which are expressed in both retinal photoreceptors and inner ear hair cells that encode proteins from distinct protein classes and families, which likely interact in a protein network critical for the development and maintenance of the sensorineural cells $(11,12)$. Molecule absence or dysfunction in the interaction of protein complexes causes network disruption with sensorineural degeneration in the retina and inner ear, which leads to USH $(5,13)$. Mutations lead to damage of certain nerve cells, such as the photoreceptors of the retina and the hair cells in the cochlea of the inner ear, causing a specific type of Usher syndrome depending on which gene locus is altered, which also affects the individual course. The affected genes are responsible for proteins that are involved in vision, hearing as well as balance. The expression of subtypes varies based on the onset and severity of hearing loss and whether vestibular dysfunction is present or absence (7).

Even though USH is traditionally divided into three subtypes, within the framework of onset and severity of common characteristics of hearing loss, presence or absence of vestibular symptoms, there may be a substantial overlap between the several clinical types with possible clinical variability in presentation and atypical presentations in all USH types (7).

\section{Usher Syndrome Subtypes}

Usher syndrome type 1 is characterized by profound sensorineural congenital hearing loss combined with pre-pubertal onset of retinitis pigmentosa and severe vestibular dysfunction (14). Causing congenital deafness, constant vestibular deficiency, and prepubertal retinitis pigmentosa with se- vere progression leading to blindness, USH1 is the most severe form of USH (15). Current data show that at least five genes (USH1B (MYO7A), USH1C (harmonin), USH1D, USH1F (PCDH15), USH1G (SANS) and possibly CIB2 $(4,16)$ and seven loci have been described for USH1 families (12). Mutation in the MYO7A gene is the most common in USH1 cases and was reported to be responsible for the subtype USH1B (17) in about $29 \%$ to $75 \%$ of cases (18-21). MYO7A mutations are the most common cause of USH1, followed by mutations in $\mathrm{CDH} 23$ and PCDH15 (22).

Based on clinical features, patients with USH1 present with vestibular dysfunction from birth and progressive vision loss due to retinitis pigmentosa (RP) (22) within the first decade of life with loss of vision by mid-life as well as severe to profound bilateral congenital sensorineural hearing loss $(6,23)$.

However, wide phenotypic variations are possible and the cause for phenotype-genotype associations between the MYO7A mutations and the multiplicity of clinical symptoms are not entirely comprehended (24).

The second of the three recognized clinical subtypes, USH2 is characterized by congenital moderate to severe hearing loss, a slightly later onset of $R P$ during or after puberty and no vestibular dysfunction (25). Different than USH1, USH2 is slightly milder, but is the most common subtype and accounts for approximately two-thirds of USH patients (26).

Even though USH1 and USH2 are in one group, clinical symptoms differ noticeably. In USH2 vestibular symptoms are not present, hearing loss is less severe and the onset of progressive retinal degeneration in the form of retinopathy pigmentosa occurs later (16).

In association with USH2 three genes have been identified including USH2A, GPR98 (USH2C), and DFNB31 (USH2D) (26).

In most populations USH3 is the most rarely represented form of the USH group with approximately $2-4 \%$ of all cases $(6,27)$. An exception in this regard was described in Finnish (28) and Ashkenazi Jewish populations $(26,29)$. The gene responsible for USH3 has been identified as the USH3A (clarin-1) gene (30). 
Unlike the other types, patients with USH3 are asymptomatic at birth and show normal physiology and develop symptoms later in life with exhibition by mid-life of progressive deterioration of hearing and deafness with variable balance disorder and late variable occurrence of RP $(4,31,32)$ induced by mutations in the gene encoding clarin-1 $(33,34)$.

Like the other types of USH, there is no available treatment for USH3 patients at present, neither to stop or to slow down the progression of the disease (33). There are options to symptomatically support patients for better management of symptoms, and also new therapeutic strategies that are based on new technologies including stem cell therapies, and gene replacement therapy are emerging (22).

Where auditory impairment can be assisted by the help of bilateral hearing aid devices, there is currently no therapy available for $\mathrm{RP}$, which is a difficult challenge for the patients and present research communities.

\section{Clinical Presentation of Vison Loss in Usher Syndrome Patients}

Retinitis pigmentosa is a group of progressive bilateral degeneration of the rod and cone photoreceptors that are characterized first by night blindness that is followed by visual-field loss, resulting in severe visual impairment (35).

The attention toward RP is focused on the delay of the complete destruction of the photoreceptors as long as possible where in all three USH subtypes the ophthalmologic findings are presented by narrowed retinal blood vessels, intraretinal pigmentation in a bone-spicule pattern, and waxy pallor of the optic disc (36). The most common cause of recessive retinitis pigmentosa (RP) including $18 \%$ of all RP is USH2 with visual acuity loss, and constricted visual field $(1,37)$. As in other forms of RP, patients suffering from USH experience vision loss beginning with deterioration of peripheral and night vision (38).

However, RP develops with a different onset in each of the three USH subtypes with varying degrees of expression and varying vison prognosis (6).

Patients affected by USH1 usually develop RP symptoms at prepubertal age (4), with vision declining generally more severely than patients affected by USH2 $(39,40)$. Initially they present mainly with night blindness (nyctalopia), mid-periphery progres- sive visual field loss by rod photoreceptor degeneration (6), reaching tunnel vision within the first decade of life. In the course the cone photoreceptors are involved with central blindness and patients reach the stage of legal blindness by midlife, in a period of 15 years on average, due to RP $(9,41)$. In retinal imaging patients present with signs of bone spicule pigmentation, atrophy or depigmentation of the retinal pigment epithelium, pallor of the optic disc, and attenuation of the retinal arterioles (6) with possible cataract and macular edema formation in the course of the disease $(9,21)$.

USH2 patients usually have a later onset of RP, mostly within the first two decades of life (42) with useful but impaired vision into middle age (43).

The rarest type, USH3, is characterized by postlingual progressive hearing loss and variable late onset of RP and vestibular dysfunction (44).

\section{MANAGEMENT}

The clinical diagnosis of USH can be demanding due to the various USH phenotypes, atypical forms of USH, and similarity to other syndromes (21). Unfortunately, little information is known of USH protein function, especially in the retina, with the consideration that the designated genes encode proteins believed to conduct various cellular functions and that the USH proteins may function in multiprotein complexes in vivo (44). Thus, much effort with much research work on solving pathophysiology and genetics of USH has been done (22). It is to date incurable, which leads to the fact that it is important to diagnose patients with USH early.

In order to provide information on the USH subtype and determine the severity of the disease, patients should receive clinical geneticist consultation and genetic testing. This may identify USH patients before retinal involvement and may give them the chance to profit from novel gene therapy (45).

Ophthalmic evaluation should include fundus photography, dynamic visual field examination, Ganzfeld-ERG with a full-field electroretinography (ERG) to confirm the dysfunction or loss of functionality of photoreceptors and optical coherence tomography (OCT) to obtain cross-sectional images of the retina to reveal possible cystic changes of the macular region or reduced central foveal thickness associated with attenuation of the RPE layer and loss of 
the photoreceptor layer $(36,46,47)$. Further audiometry, otoscopy, and balance evaluation with electronystagmography to measure involuntary eye movement (48).

As mentioned above, there is no known treatment for USH and no approved treatment for the vision loss associated with RP (37). The treatment mainly concerns interventions to slow down the progress of the disease (46), with possible vitamin A palmitate (49), appropriate visual and hearing aids.

A large amount of gene research focuses on USH with gene-based therapies, genome editing, and numerous therapeutic strategies $(50,51)$ with the hope to even better help USH patients in near future and improve their quality of life.

\section{CONCLUSION}

Usher syndrome is a group of genetically autosomal recessive disorders characterized by clinically variable hearing loss and gradual visual impairment secondary to RP and possible vestibular dysfunction. Considering that the affected persons often lose two of their vital human senses or can only use them in an impaired way, Usher syndrome must be considered as a disease that severely limits the quality of life of the patient. This is probably also one of the reasons why research has been making remarkable steps with USH gene identification and understanding syndrome pathogenesis. In view of the positive results of the current studies, we wish that further developed therapy approaches and supportive methods will be available.

\section{REFERENCES}

1. Boughman JA, Vernon M, Shaver KA. Usher syndrome: definition and estimate of prevalence from two high-risk populations. J Chronic Dis. 1983;36(8):595-603. doi: 10.1016/0021-9681(83)90147-9.

2. Kimberling WJ, Hildebrand MS, Shearer AE, Jensen ML, Halder JA, Trzupek K, et al. Frequency of Usher syndrome in two pediatric populations: Implications for genetic screening of deaf and hard of hearing children. Genet Med. 2010;12(8):512-6. doi: 10.1097/GIM.0b013e3181e5afb8.

3. Vernon M. Usher's syndrome--deafness and progressive blindness. Clinical cases, prevention, theory and literature sur- vey. J Chronic Dis. 1969;22(3):133-51. doi: 10.1016/0021-9681(69)90055-1.

4. Kremer H, van Wijk E, Märker T, Wolfrum U, Roepman R. Usher syndrome: molecular links of pathogenesis, proteins and pathways. Hum $\mathrm{Mol}$ Genet. 2006;15 Spec No 2:R262-70. doi: 10.1093/ hmg/ddl205.

5. Reiners J, Nagel-Wolfrum K, Jürgens K, Märker T, Wolfrum U. Molecular basis of human Usher syndrome: deciphering the meshes of the Usher protein network provides insights into the pathomechanisms of the Usher disease. Exp Eye Res. 2006;83(1):97-119. doi: 10.1016/j.exer.2005.11.010.

6. Toms M, Pagarkar W, Moosajee M. Usher syndrome: clinical features, molecular genetics and advancing therapeutics. Ther Adv Ophthalmol. 2020;12:2515841420952194. doi: $10.1177 / 2515841420952194$.

7. Cohen M, Bitner-Glindzicz M, Luxon L. The changing face of Usher syndrome: clinical implications. Int J Audiol. 2007;46(2):82-93. doi: 10.1080/14992020600975279.

8. Germiller JA. Hearing loss in children. In: Wetmore RF, editor. Pediatric otolaryngology: the requisites in pediatrics. Philadelphia, PA: Mosby Elsevier. 2007. pp. 60-76.

9. Koenekoop RK, Arriaga MA, Trzupek KM, Lentz JJ. Usher Syndrome Type 1. Definitions, Qeios. 2020.

10. Ebermann I, Scholl HP, Charbel Issa P, Becirovic E, Lamprecht J, Jurklies B, et al. A novel gene for Usher syndrome type 2: mutations in the long isoform of whirlin are associated with retinitis pigmentosa and sensorineural hearing loss. Hum Genet. 2007;121(2):203-11. doi: 10.1007/ s00439-006-0304-0.

11. Reiners J, van Wijk E, Märker T, Zimmermann U, Jürgens K, te Brinke H, Overlack N, Roepman R, Knipper M, Kremer H, Wolfrum U. Scaffold protein harmonin (USH1C) provides molecular links between Usher syndrome type 1 and type 2. Hum Mol Genet. 2005;14(24):3933-43. doi: 10.1093/hmg/ ddi417.

12. Yan D, Liu XZ. Genetics and pathological mechanisms of Usher syndrome. J Hum Genet. 2010;55(6):327-35. doi: 10.1038/jhg.2010.29.

13. El-Amraoui A, Petit C. The retinal phenotype of Usher syndrome: pathophysiological insights from 
Catherina Bommert, Elitsa Hristova, Christina Grupcheva

animal models. C R Biol. 2014;337(3):167-77. doi: 10.1016/j.crvi.2013.12.004.

14. Yan J, Pan L, Chen X, Wu L, Zhang M. The structure of the harmonin/sans complex reveals an unexpected interaction mode of the two Usher syndrome proteins. Proc Natl Acad Sci U S A. 2010;107(9):4040-5. doi: 10.1073/pnas.0911385107.

15. Jaijo T, Aller E, Beneyto M, Najera C, Graziano C, Turchetti D, Seri M, Ayuso C, Baiget M, Moreno F, Morera C, Perez-Garrigues H, Millan JM. MYO7A mutation screening in Usher syndrome type I patients from diverse origins. J Med Genet. 2007;44(3):e71. doi: 10.1136/jmg.2006.045377.

16. Reiners J, Wolfrum U. Molecular analysis of the supramolecular usher protein complex in the retina. Harmonin as the key protein of the Usher syndrome. Adv Exp Med Biol. 2006;572:349-53. doi: 10.1007/0-387-32442-9_49.

17. Sahly I, El-Amraoui A, Abitbol M, Petit C, Dufier JL. Expression of myosin VIIA during mouse embryogenesis. Anat Embryol (Berl). 1997;196(2):15970. doi: 10.1007/s004290050088.

18. 18. Jaijo T, Aller E, Oltra S, Beneyto M, Nájera C, Ayuso C, et al. Mutation profile of the MYO7A gene in Spanish patients with Usher syndrome type I. Hum Mutat. 2006;27(3):290-1. doi: 10.1002/ humu.9404.

19. Roux AF, Faugère V, Le Guédard S, Pallares-Ruiz N, Vielle A, Chambert S, et al. Survey of the frequency of USH1 gene mutations in a cohort of Usher patients shows the importance of cadherin 23 and protocadherin 15 genes and establishes a detection rate of above $90 \%$. J Med Genet. 2006;43(9):763-8. doi: 10.1136/jmg.2006.041954.

20. Bharadwaj AK, Kasztejna JP, Huq S, Berson EL, Dryja TP. Evaluation of the myosin VIIA gene and visual function in patients with Usher syndrome type I. Exp Eye Res. 2000;71(2):173-81. doi: 10.1006/ exer.2000.0863.

21. Dad S, Rendtorff ND, Tranebjærg L, Grønskov K, Karstensen HG, Brox V, et al. Usher syndrome in Denmark: mutation spectrum and some clinical observations. Mol Genet Genomic Med. 2016;4(5):527-39. doi: 10.1002/mgg3.228.

22. Whatley M, Francis A, Ng ZY, Khoh XE, Atlas MD, Dilley RJ, Wong EYM. Usher syndrome: Genetics and molecular links of hearing loss and directions for therapy. Front Genet. 2020;11:565216. doi: 10.3389/fgene.2020.565216.
23. Hope CI, Bundey S, Proops D, Fielder AR. Usher syndrome in the city of Birmingham--prevalence and clinical classification. Br J Ophthalmol. 1997;81(1):46-53. doi: 10.1136/bjo.81.1.46.

24. Lu Y, Zhou D, King R, Zhu S, Simpson CL, Jones $\mathrm{BC}$, et al. The genetic dissection of Myo7a gene expression in the retinas of BXD mice. Mol Vis. 2018;24:115-26.

25. Jung J. The era of precision medicine: Reshaping Usher syndrome. Clin Exp Otorhinolaryngol. 2020;13(2):87-8. doi: 10.21053/ceo.2019.02117.

26. 26. Millán JM, Aller E, Jaijo T, Blanco-Kelly F, Gimenez-Pardo A, Ayuso C. An update on the genetics of usher syndrome. J Ophthalmol. 2011;2011:417217. doi: 10.1155/2011/417217.

27. Jouret G, Poirsier C, Spodenkiewicz M, Jaquin C, Gouy E, Arndt C, et al. Genetics of Usher syndrome: New insights from a meta-analysis. Otol Neurotol. 2019;40(1):121-9. doi: 10.1097/ MAO.0000000000002054.

28. Pakarinen L, Karjalainen S, Simola KO, Laippala P, Kaitalo H. Usher's syndrome type 3 in Finland. Laryngoscope. 1995;105(6):613-7. doi: 10.1288/00005537-199506000-00010.

29. Ness SL, Ben-Yosef T, Bar-Lev A, Madeo AC, Brewer CC, Avraham KB, et al. Genetic homogeneity and phenotypic variability among Ashkenazi Jews with Usher syndrome type III. J Med Genet. 2003 Oct;40(10):767-72. doi: 10.1136/jmg.40.10.767.

30. Adato A, Vreugde S, Joensuu T, Avidan N, Hamalainen R, Belenkiy O, et al. USH3A transcripts encode clarin-1, a four-transmembrane-domain protein with a possible role in sensory synapses. Eur J Hum Genet. 2002 Jun;10(6):339-50. doi: 10.1038/ sj.ejhg. 5200831.

31. Fields RR, Zhou G, Huang D, Davis JR, Möller C, Jacobson SG, et al. Usher syndrome type III: revised genomic structure of the USH3 gene and identification of novel mutations. Am J Hum Genet. 2002;71(3):607-17. doi: 10.1086/342098.

32. Nyberg S, Abbott NJ, Shi X, Steyger PS, Dabdoub A. Delivery of therapeutics to the inner ear: The challenge of the blood-labyrinth barrier. Sci Transl Med. 2019;11(482):eaao0935. doi: 10.1126/scitranslmed.aao0935.

33. Alagramam KN, Gopal SR, Geng R, Chen DH, Nemet I, Lee R, et al. A small molecule mitigates hearing loss in a mouse model of Usher syndrome 
III. Nat Chem Biol. 2016;12(6):444-51. doi: 10.1038/ nchembio.2069.

34. Joensuu T, Hämäläinen R, Yuan B, Johnson C, Tegelberg S, Gasparini P, et al. Mutations in a novel gene with transmembrane domains underlie Usher syndrome type 3. Am J Hum Genet. 2001 Oct;69(4):673-84. doi: 10.1086/323610.

35. Kaiserman N, Obolensky A, Banin E, Sharon D. Novel USH2A mutations in Israeli patients with retinitis pigmentosa and Usher syndrome type 2. Arch Ophthalmol. 2007;125(2):219-24. doi: 10.1001/ archopht.125.2.219.

36. Severe retinal degeneration at an early age in Usher syndrome type $1 \mathrm{~B}$ associated with homozygous splice site mutations in MYO7A gene. Saudi J Ophthalmol. 2018;32(2):119-25. doi: 10.1016/j. sjopt.2017.10.004.

37. Falsini B, Placidi G, De Siena E, Savastano MC, Minnella AM, Maceroni M, Midena G, Ziccardi L, Parisi V, Bertelli M, Maltese PE, Chiurazzi P, Rizzo S. USH2A-related retinitis pigmentosa: staging of disease severity and morpho-functional studies. Diagnostics (Basel). 2021;11(2):213. doi: 10.3390/ diagnostics11020213.

38. Williams DS. Retinal degeneration in Usher syndrome. In: Tombran-Tink J, Barnstable CJ, editors. Retinal degenerations. Totowa, NJ: Humana Press; 2007. pp. 137-48.

39. Testa F, Melillo P, Bonnet C, Marcelli V, de Benedictis A, Colucci R, et al. clinical presentation and disease course of Usher syndrome because of mutations in MYO7A OR USH2A. Retina. 2017;37(8):1581-90. doi: 10.1097/ IAE.0000000000001389.

40. Blanco-Kelly F, Jaijo T, Aller E, Avila-Fernan$\operatorname{dez}$ A, López-Molina MI, Giménez A, et al. Clinical aspects of Usher syndrome and the USH2A gene in a cohort of 433 patients. JAMA Ophthalmol. 2015;133(2):157-64. doi: 10.1001/ jamaophthalmol.2014.4498.

41. Lenassi E, Saihan Z, Cipriani V, Le Quesne Stabej P, Moore AT, Luxon LM, Bitner-Glindzicz M, Webster AR. Natural history and retinal structure in patients with Usher syndrome type 1 owing to MYO7A mutation. Ophthalmology. 2014;121(2):580-7. doi: 10.1016/j.ophtha.2013.09.017.

42. Smith RJ, Berlin CI, Hejtmancik JF, Keats BJ, Kimberling WJ, Lewis RA, et al. Clinical diagnosis of the Usher syndromes. Usher Syndrome Con- sortium. Am J Med Genet. 1994;50(1):32-8. doi: 10.1002/ajmg.1320500107.

43. Mets MB, Young NM, Pass A, Lasky JB. Early diagnosis of Usher syndrome in children. Trans Am Ophthalmol Soc. 2000;98:237-42; discussion 243-5.

44. Mathur P, Yang J. Usher syndrome: Hearing loss, retinal degeneration and associated abnormalities. Biochim Biophys Acta. 2015;1852(3):406-20. doi: 10.1016/j.bbadis.2014.11.020.

45. Bolz HJ. Usher syndrome: Diagnostic approach, differential diagnoses and proposal of an updated function-based genetic classification. Medizinische Genet. 2020; 32(2):131-40. doi:10.1515/ medgen-2020-2023.

46. Seeliger MW, Fischer MD, Pfister M. Klinik, Diagnostik und Behandlungsoptionen des Usher-Syndroms. Ophthalmologe. 2009;106(6):505-11. doi: 10.1007/s00347-008-1888-7.

47. Stingl K, Kurtenbach A, Hahn G, Kernstock C, Hipp S, Zobor D, et al. Full-field electroretinography, visual acuity and visual fields in Usher syndrome: a multicentre European study. Doc Ophthalmol. 2019;139(2):151-60. doi: 10.1007/ s10633-019-09704-8.

48. Pater JA, Green J, O'Rielly DD, Griffin A, Squires J, Burt T, et al. Novel Usher syndrome pathogenic variants identified in cases with hearing and vision loss. BMC Med Genet. 2019;20(1):68. doi: 10.1186/ s12881-019-0777-z.

49. Berson EL, Rosner B, Sandberg MA, Hayes KC, Nicholson BW, Weigel-DiFranco C, Willett W. A randomized trial of vitamin $\mathrm{A}$ and vitamin $\mathrm{E}$ supplementation for retinitis pigmentosa. Arch Ophthalmol. 1993;111(6):761-72. doi: 10.1001/ archopht.1993.01090060049022.

50. Lopes VS, Boye SE, Louie CM, Boye S, Dyka F, Chiodo V, et al. Retinal gene therapy with a large MYO7A cDNA using adeno-associated virus. Gene Ther. 2013;20(8):824-33. doi: 10.1038/gt.2013.3.

51. Zallocchi M, Binley K, Lad Y, Ellis S, Widdowson P, Iqball S, et al. EIAV-based retinal gene therapy in the shakerl mouse model for usher syndrome type 1B: development of UshStat. PLoS One. 2014;9(4):e94272. doi: 10.1371/journal. pone.0094272. 